\title{
Building the Capacity of the Next-Generation Philippine Occupational Therapy Academic Workforce: Insights from an Occupational Profile Study
}

\author{
Maria Concepcion C. Cabatan, PhD, ${ }^{1}$ Lenin C. Grajo, PhD, OTR/L ${ }^{2}$ and Erlyn A. Sana, $\mathrm{PhD}^{3}$ \\ ${ }^{1}$ Department of Occupational Therapy, College of Allied Medical Professions, University of the Philippines Manila \\ ${ }^{2}$ Programs in Occupational Therapy, Department of Rehabilitation and Regenerative Medicine, \\ Vagelos College of Physicians and Surgeons, Columbia University, New York, NY \\ ${ }^{3}$ National Teacher Training Center for the Health Professions, University of the Philippines Manila
}

\begin{abstract}
Background. Occupational therapy (OT) academic educators are vital in building the workforce and advancing the profession. With the retirement of senior faculty, hiring of new OT faculty members have increased. There have also been changes in national and global policy guidelines in OT education. These changes have brought forth a compelling need to examine the profile of Filipino OT educators. To this date, there has been no formal analysis of the Philippine OT academic education workforce. A study aiming at understanding this profile is important to inform OT educators, administrators, and policymakers on the development of strategic approaches that may address their needs and help build the capacity of this workforce.
\end{abstract}

Objectives. We aimed to establish an occupational profile of OT educators in the Philippines and to recommend capacity-building strategies for next-generation Filipino OT educators.

Methods. A cross-sectional survey was conducted using the Adaptation Process in Academia Questionnaire. OT educators were recruited through their institutional affiliations.

Results. Ninety (53\%) of the estimated 170 educators participated in the study, representing 16 schools with OT programs in the country. The median age is 26 years, majority female, and single. The academic profile shows that the majority have a bachelor's as their highest educational degree, work part-time, hold the instructor rank, nontenured, and have been in academia for $5+$ years. Teaching is the primary role, and $>50 \%$ of the time is spent on teaching tasks. The most frequently experienced challenges are balancing multiple roles and the need to develop competence in research skills. Most effective institutional resources are the availability of teaching resources and orientation programs. Excellent communication between university management and academic staff and the opportunity to participate in decision-making are perceived to be the most useful relationship support. Productivity in teaching is higher than in research and service.

Conclusion. The current OT academic workforce based on this study is young, in the early career stage, and expected to assume many roles, primarily teaching. They are most challenged in balancing multiple roles and how to advance their academic careers. Institutional resources and relationship supports are available but need to be reinforced and accessed. Strategic initiatives to build capacity include the development of communities of practice, increasing research engagement and productivity, increasing access to professional development programs, and faculty development initiatives.

Key Words: faculty, occupational therapy, university, capacity building, Philippines

Corresponding author: Maria Concepcion C. Cabatan, PhD

Department of Occupational Therapy

College of Allied Medical Professions

University of the Philippines Manila

Pedro Gil St., Ermita, Manila 1000

Email: mdcabatan@up.edu.ph 


\section{INTRODUCTION}

Globally, the changing higher education environment and health systems challenge the health professions academic workforce with the increase in hiring of new faculty on temporary contracts. ${ }^{1,2}$ Referred to as next-generation faculty, ${ }^{3,4}$ the younger educators represent the future of the academic workforce. ${ }^{4}$ They are characterized as more familiar with communication technologies, use a variety of approaches in their academic careers, and more particular about collaboration, collegial relationships, and worklife balance. ${ }^{5}$

Literature has documented efforts to understand the next-generation faculty in the early career stage (i.e., educators in the first five years of an academic appointment) in many disciplines including the health sciences such as occupational therapy, physical therapy, and nursing., ${ }^{2,6-9}$ In developed economies, next-generation faculty have completed or are completing terminal academic degrees. Because of intense competition for permanent positions, difficult work experiences, career uncertainty, and instability pervade among early career academics. ${ }^{6,10}$

Balancing teaching, research, and service is the most challenging task that early-career academics face because of high teaching workloads.,11 Their academic identity is anchored on teaching. Increased demands and over-commitment to work have caused disengagement and burnout among early-career academics. ${ }^{5}$ McCune $^{12}$ reported that faculty in research-intensive universities sustained their teaching identities by giving meaning to their teaching role, despite struggles and tensions with other professional identities.

Professional development and capacity building are critical for early career academics to pursue a successful career in the academe, even those with advanced degrees.,10 There is evidence that graduate programs do not adequately prepare faculty with skills to be successful in academia. ${ }^{3}$ Capacity building in higher education institutions must address challenges such as recruitment and selection, learning and development, and performance of its human resources. ${ }^{13}$ Silva et al. ${ }^{13}$ proposed the use of capacity building frameworks that focus on competencies that will enable academic staff to improve performance in their respective institutions. The faculty learning community (FLC) approach to building the capacity of new academics has gained popularity because it addresses their needs and characteristics. ${ }^{3}$ This model espouses the development of professional competencies characterized by intentional community building, collaboration, flexibility, and interactivity with the academic culture. ${ }^{3}$

The learning community approach can vary in terms of structure, goals, and participants. ${ }^{3}$ For example, BeaneKatner $^{3}$ proposed that it can be cohort-based if the intent is to address the needs of a specific group of faculty, or it can be topic-based, to cover subjects of interest or importance to a group of faculty from different disciplines. This model has been applied to mentoring and other support systems. ${ }^{4,6}$ Instead of the traditional paired mentoring, a diverse team of mentors provide support to new faculty. ${ }^{6}$ Mentoring drawn from the learning community approach has been reported to be valuable for good job performance and transitioning to academic roles among new or early-career academics. ${ }^{14}$ Support is especially crucial for part-time, adjunct, or contractual faculty who do not have access to support networks in academic work environments. ${ }^{15}$

\section{OCCUPATIONAL THERAPY EDUCATORS}

There have been renewed interest and attention on the occupational therapy (OT) academic workforce, the focus of this study, due to the increase in schools offering OT programs, the retirement of senior faculty, and changes in health care and higher education policy. ${ }^{16,17}$ Adjunct OT faculty describe their lack of competence in pedagogy despite being viewed as content experts. ${ }^{15}$ New full-time faculty were unprepared for roles and unforeseen responsibilities such as participating in committees and interviewing for admissions. ${ }^{16}$ OT clinicians transitioning to academic roles experienced feelings of doubt and incompetence as educators. ${ }^{18}$ Furthermore, heavy teaching loads leave no time for OT and health professions faculty to engage in research endeavors. ${ }^{19,20}$ To be research-productive, the working environment must be fostered in a caring, collaborative, and collegial space. ${ }^{20,21}$ Junior tenure-track faculty who needed to increase their research productivity reported burnout and a lack of job satisfaction and confidence in their research skills. ${ }^{22}$

\section{THE CONTEXT OF PHILIPPINE OCCUPATIONAL THERAPY EDUCATION}

Philippine OT education and practice have been influenced by foreign labor markets and migration to developed countries (e.g., United States). ${ }^{23}$ Over the past three decades, the number of OT programs and enrolment trends follows the demand for OTs in employment markets abroad. ${ }^{23}$ In recent years, higher entry-level OT degree requirements in Western countries have mitigated migration. ${ }^{23}$

The World Health Organization's (WHO) Rehabilitation 2030: A Call for Action, ${ }^{24}$ the World Federation of Occupational Therapists (WFOT) Minimum Standards for the Education of Occupational Therapists, ${ }^{25}$ and the Commission on Higher Education (CHED) Policies, Standards and Guidelines for the (BSOT) program ${ }^{26}$ have resulted in the agenda that calls for producing a critical mass of occupational therapists, revising the Bachelor of Science in OT curricula, and upgrading qualifications of Filipino occupational therapy academic educators. ${ }^{23}$ The Philippine Academy of Occupational Therapists, Inc. (PAOT) aims to have one OT per 20,000 Filipinos by 2025. ${ }^{27}$ Also, the Philippine Universal Health Care $\mathrm{Act}^{28}$ will further 
affect changes in occupational therapy curricula to prepare graduates to work at the primary care level.

These developments highlight the importance of examining the occupational profile of Philippine-based OT educators who play a critical role in meeting the agenda of the WHO Rehabilitation 2030 and CHED. There is no official government data that describe the characteristics of the OT professional population, including educators. ${ }^{29}$ This study is crucial in understanding academic roles expectations and demands, challenges, institutional resources, relationship supports, and productivity. ${ }^{30}$ This information will inform policymakers, and university administrators formulate and strengthen strategies to build capacity and support the advancement of academic careers of Filipino OT educators. For this study, we define occupational profile as a summary of demographics, academic characteristics, role expectations and demands, academic challenges, institutional resources, relationship supports, and productivity.

This study aimed to address the following research objectives:

1. Describe the demographic and academic characteristics of Filipino OT educators working in Philippine OT schools.

2. Explain the perceptions of Filipino OT educators on their role expectations and demands, academic challenges, institutional resources, relationship supports, and productivity.

3. Draw capacity-building strategies that address the characteristics and perceptions of Filipino OT educators.

\section{METHODS}

\section{Design}

We utilized a cross-sectional design to obtain survey data for a national profile. This design is cost-effective and convenient in gathering data within a set period. ${ }^{31} \mathrm{We}$ obtained ethics approval from the first author's Research Ethics Board.

\section{Study setting}

The setting for this study included academic institutions in the Philippines where Filipino OT educators work. The CHED identified twenty institutions that are operational. Nineteen are private institutions.

\section{Participants and Sampling}

We invited all Filipino OT faculty $(N=170)$ who fulfilled the following selection criteria: (1) currently working in an academic institution on a temporary or permanent status; (2) working on full-time or part-time basis; and (3) who will consent to participate in the study. We excluded faculty who were retiring within the next two years. The recruitment and selection of participants allowed representation of OT faculty from across the higher education institutions offering Bachelor of Science in Occupational Therapy in different parts of the Philippines from as many participants recruited for this study. This participation was made possible despite the lack of a database of OT faculty members in the Philippines from government or professional organizations.

A total of 90 (53\%) faculty participated. They represented 16 (out of 20) OT schools in the Philippines. From the 90 participants, 63 were from Luzon, the North Island, 20 from the Visayas, the Central Islands, and seven from the South Island of Mindanao. One participant did not identify the institution. Four schools (three in Luzon and one in Mindanao) did not respond, despite repeated invitations.

\section{Instrument}

From literature, we developed the Adaptation Process in Academia Questionnaire (APA-Q). 2,32,33 Questions in the APA-Q are drawn from concepts of the Occupational Adaptation Theory to understand educators' process of adaptation to academic roles. ${ }^{34}$

For this study, we present results of the first two sections: The first section asked for demographic characteristics (age, sex, civil status, highest educational degree, educational degrees to be completed or pursued, clinical experience) and academic characteristics (appointment status [full-time/parttime, tenured/temporary], rank, and reasons for joining the academe). The second section is described in Table 1. As part of voluntary participation, participants were encouraged to answer all but given the option to refuse to answer questions.

The APA-Q underwent content validation ${ }^{34}$ and was revised based on expert feedback and findings from a separate construct validation study. Using content validity index analysis, the APA-Q was found to have over-all item relevance based on scale-content validity index $(\mathrm{S}-\mathrm{CVI}=0.97)$. Using a partial least squares structural equation modeling approach for construct validation, the APA- $Q$ showed adequate internal consistency reliability $(\alpha=0.761)$, convergent validity (average variance extracted $[\mathrm{AVE}]=0.540-0.865$; indicator loadings $=0.511-0.930$ ), and discriminant validity (square root of the AVE $[\mathrm{S}-\mathrm{AVE}]=0.735-0.856$ ).

\section{Data collection}

Data were collected from June to July 2019. Participants were recruited through letters of invitation to OT department chairpersons of all schools and the PAOT. The invitations contained the link to the online questionnaire and consent form. We did not ask for names to ensure anonymity and voluntary participation. We sent reminder letters every week to all faculty through the department chairpersons and the PAOT.

\section{Data analysis}

We analyzed the dataset on Stata/IC 15.1 (StataCorp LLC, Texas) using descriptive statistics such as frequency and percentage distributions, means, and standard deviations. Responses counted as frequency distributions are considered meaningful if they meet the cut-off score of 
Table 1. Description of the APA-Q (First Two Sections)

\begin{tabular}{|c|c|c|c|c|}
\hline Variable & Definition & No. of items & Sample items & Scale \\
\hline $\begin{array}{l}\text { Role } \\
\text { expectations } \\
\text { and demands }\end{array}$ & $\begin{array}{l}\text { Duties and } \\
\text { responsibilities expected } \\
\text { for a given role, such } \\
\text { as participation in } \\
\text { teaching, research, and } \\
\text { service activities. }\end{array}$ & 8 & $\begin{array}{l}\text { - Preferred and expected roles } \\
\text { - Level of program taught (BSOT, Master of OT), } \\
\text { - Year levels taught } \\
\text { - Number of courses } \\
\text { - Number of thesis students supervised } \\
\text { - Number of research projects involved in, } \\
\text { - Number of service activities involved in }\end{array}$ & $\begin{array}{l}\text { Participants asked to select } \\
\text { one from given choices } \\
\text { Participants provided number }\end{array}$ \\
\hline $\begin{array}{l}\text { Academic } \\
\text { challenges }\end{array}$ & $\begin{array}{l}\text { Situations or conditions } \\
\text { experienced within the } \\
\text { academic environment as } \\
\text { they fulfilled role expec- } \\
\text { tations and demands. }\end{array}$ & 30 & $\begin{array}{l}\text { Challenges related to: } \\
\text { - Shift of role (emotional stress due to workload) } \\
\text { - Balancing multiple roles } \\
\text { - Embracing academic culture } \\
\text { - Career advancement }\end{array}$ & $\begin{array}{l}\text { Ratings of frequency: } \\
\text { Five-point Likert scale } \\
\text { (Almost always - never) }\end{array}$ \\
\hline $\begin{array}{l}\text { Institutional } \\
\text { resources }\end{array}$ & $\begin{array}{l}\text { Resources that may/ } \\
\text { may not be available at } \\
\text { the academic institution } \\
\text { that support fulfillment } \\
\text { of roles. }\end{array}$ & 18 & $\begin{array}{l}\text { Resource related to: } \\
\text { - Teaching development } \\
\text { - Workload/Research Support and Information } \\
\text { - Flexibility/Rewards and Benefits }\end{array}$ & $\begin{array}{l}\text { Ratings of effectiveness: } \\
\text { Four-point Likert scale } \\
\text { (Very effective - very } \\
\text { ineffective; Not available/ } \\
\text { Not accessed) }\end{array}$ \\
\hline $\begin{array}{l}\text { Relationship } \\
\text { supports }\end{array}$ & $\begin{array}{l}\text { Nurturing and influential } \\
\text { relationships provided } \\
\text { by the institution and } \\
\text { the department. }\end{array}$ & 15 & $\begin{array}{l}\text { - Support from the institution } \\
\text { - Support from the department }\end{array}$ & $\begin{array}{l}\text { Ratings of effectiveness: } \\
\text { Four-point Likert scale } \\
\text { (Very effective - very } \\
\text { ineffective; Not available/ } \\
\text { Not accessed) }\end{array}$ \\
\hline Productivity & $\begin{array}{l}\text { Number of outputs } \\
\text { related to teaching, } \\
\text { research, service. }\end{array}$ & 29 & $\begin{array}{l}\text { - Revised or developed new curriculum } \\
\text { - Published articles in peer-reviewed journals } \\
\text { - I have received an internal university service award }\end{array}$ & $0-5$ or more \\
\hline
\end{tabular}

Table 2. Participants' Demographic Information ( $N=90)$

\begin{tabular}{lllrr}
\multicolumn{1}{c}{ Profile } & N & \multicolumn{1}{c}{ Characteristic } & $\mathbf{n}$ & \multicolumn{1}{c}{$\%$} \\
Civil status & 90 & Single & 71 & 78.90 \\
& & Married & 14 & 15.60 \\
& Partnered & 3 & 3.30 \\
& Separated & 2 & 2.20 \\
\hline Highest educational & 90 & BSOT & 63 & 70.00 \\
degree & MA/MS in OT & 11 & 12.20 \\
& & MA/MS in another discipline & 15 & 16.70 \\
& PhD/EdD/ScD & 1 & 1.10 \\
\hline Educational & MA/MS in OT & 20 & 40.00 \\
degree completing & MA/MS in another discipline & 20 & 40.00 \\
(within three years) & & 8 & 16.00 \\
& & PhD/EdD/ScD & 2 & 4.00 \\
\hline Pursuing in the & Clinical Doctorate & 7 & 7.80 \\
future (within the & MA/MS in OT & 21 & 23.33 \\
next three years) & MA/MS in another discipline & 26 & 28.89 \\
& PhD/EdD/ScD & 10 & 11.10 \\
& Clinical Doctorate & 4 & 4.44 \\
& No plans to pursue graduate studies & 22 & 24.44 \\
\hline
\end{tabular}

*Only 50 are enrolled in graduate programs

$\geq 50 \%$. Grouping of responses was done. For example, for challenges, we grouped responses of almost always, often, and sometimes as experienced, and seldom and never as not experienced. We performed cross-tabulations for select variables (e.g., preferred and expected roles, challenges) to examine subgroups: age groups $(20$ - 30, 31 - 40, 41 and up), rank (instructor, assistant professor, associate professor, professor), and highest educational degree (BS, Master's, and $\mathrm{PhD})$.

\section{RESULTS}

Participants' Demographic and Academic Profiles

The demographic information of the 90 participants is described in Table 2. The mean age of the participants is 30 years $(S D=7.78)$. Majority are female $(n=55,61.8 \%)$. The majority $(n=60 ; 66 \%)$ of the participants belong to the 21 - 30 age group. Sixteen (18\%) are 31 - 40 years old, and $14(16 \%)$ are 41 and older. Majority have been faculty for 5 
Table 3. Participants' Demographic Information ( $N=90)$

\begin{tabular}{lrr} 
& \multicolumn{2}{c}{ Current } \\
& (at the time of survey) \\
\cline { 2 - 3 } & $\mathbf{n}$ & $\%$ \\
Time Classification & & \\
$\quad$ Full-time & 40 & 44.44 \\
Part-time & 50 & 55.56 \\
\hline Academic rank & & \\
Instructor & 44 & 48.90 \\
Assistant professor & 12 & 13.33 \\
Associate professor & 2 & 2.20 \\
Full professor & 1 & 1.10 \\
Lecturer & 8 & 8.90 \\
Clinical instructor & 17 & 18.90 \\
Others (e.g., clinical training coordinator) & 6 & 6.70 \\
\hline Years in current rank & & \\
< 1 - 4 years & 4 & 4.40 \\
5 or more years & 86 & 95.60 \\
\hline Tenure & & \\
Permanent & 11 & 12.20 \\
Temporary & 69 & 76.70 \\
Tenure-track & 7 & 7.80 \\
No tenure system & 3 & 3.30 \\
\hline
\end{tabular}

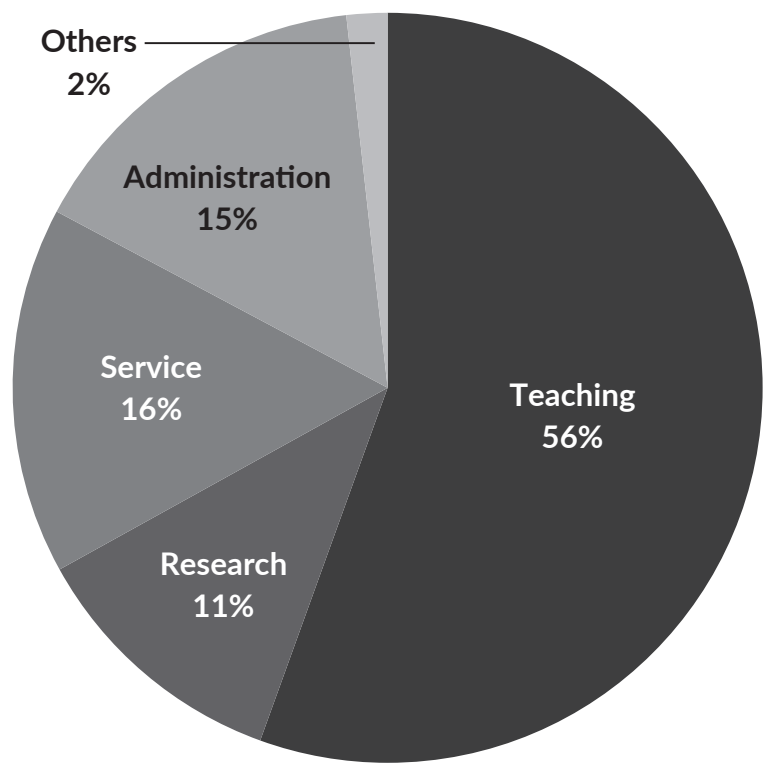

Figure 1. Mean Percentage of Actual Time Spent on Academic Activities.

Table 4. Preferred and Expected Roles* of Participants $(N=90)$

\begin{tabular}{|c|c|c|c|c|c|}
\hline Preferred & $\mathbf{n}$ & $\%$ & Expected & $\mathbf{n}$ & $\%$ \\
\hline Teaching & 15 & 16.70 & Teaching & 25 & 27.80 \\
\hline Research & 2 & 2.22 & Research & 3 & 3.30 \\
\hline Service & 2 & 2.22 & Service & 0 & 0 \\
\hline Several preferred, leaning towards teaching & 30 & 33.30 & All three, more teaching than research & 21 & 23.30 \\
\hline Several preferred, leaning towards research & 2 & 2.22 & All three, more research, than teaching & 7 & 7.80 \\
\hline Several preferred, leaning towards service & 17 & 18.90 & & & \\
\hline \multirow[t]{2}{*}{ Equally Teaching, Research, Service } & 22 & 24.44 & & 32 & 35.60 \\
\hline & & & Other & 2 & 2.20 \\
\hline
\end{tabular}

${ }^{*}$ reflect actual choices; participants were asked to choose one

or more years $(n=85 ; 95.5 \%)$. Seventy-four $(82 \%)$ are also practicing clinicians who mostly work in multiple clinical settings (clinics, schools, community-based, private practice), and more than half are practicing in pediatrics.

Academic characteristics (Table 3) show that majority are part-time, hold the instructor rank, and temporary positions. The most common reasons for joining academe are desire to share clinical expertise (91\%), want to teach (89\%), need for faculty (87\%), flexible hours, and to explore a career in the academe (82\%).

\section{Role Expectations and Demands}

Table 4 shows that although there are several preferences and expectations in terms of roles, most of these lean towards teaching. This is supported by the percentage of time spent on academic activities (Figure 1). In terms of teaching, majority ( $n=80 ; 90 \%)$ teach only at the undergraduate (BSOT) level, teach in more than one-year level $(n=65 ; 72 \%)$, and teach $1-4$ courses $(n=52 ; 58 \%)$ per academic year. More than half ( $n=60 ; 67 \%)$ are engaged in research projects, of which more than half $(n=51 ; 57 \%)$ are related to the supervision of student theses. Thirty-eight (43\%) are not engaged in the supervision of student theses. More than half ( $n=65 ; 72 \%)$ are involved in one to five or more service projects.

In terms of educational degrees, those with BS and Master's degrees prefer several roles, leaning towards teaching. The one participant with a $\mathrm{PhD}$ preferred role is in research. For the roles that they are expected to do, the BS and Master's groups are expected to assume all three roles, doing more teaching. The one participant with a $\mathrm{PhD}$ is expected to do all three roles, more research than teaching and service. It is generally the same in terms of groups pursuing advanced degrees and rank.

\section{Challenges}

Figure 2 shows that the most experienced challenges are related to balancing multiple roles and career advancement. Table 5 shows the specific challenges most and least 


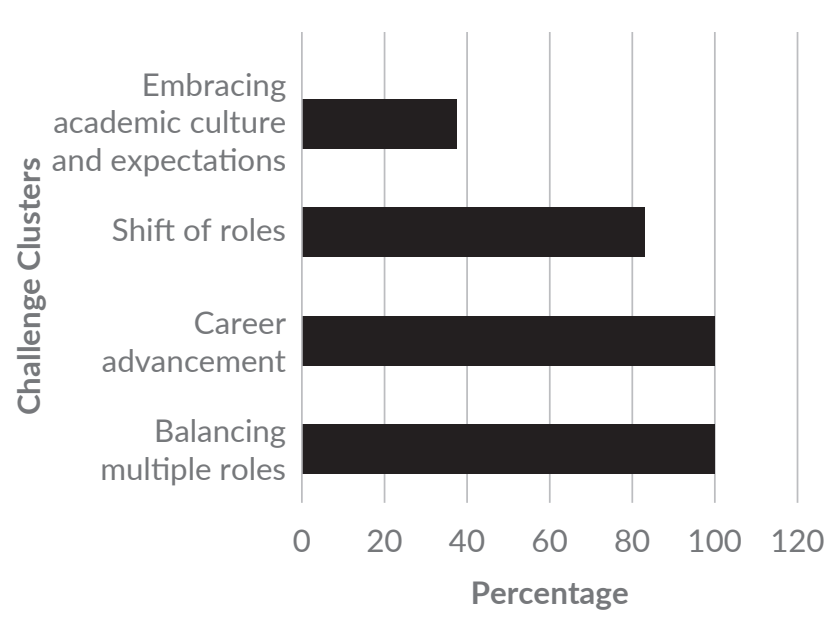

Figure 2. Percentage of Challenges Experienced Per Cluster.

experienced. The challenges of the shift of roles cluster are mostly experienced by those in the 21 - 30 age group. The challenge of dealing with unexpected roles and tasks is most prominent for the 21 - 30 and 31 - 40 age group. The challenges of no time for research and how to advance a career are foremost for all age groups. The challenges of meeting promotion, tenure, and pressure to publish are distinct for the age groups 31 - 40 and 40 and up.

In terms of rank, adjusting from clinician/student to faculty role is most prominent among the instructors and lecturers. Developing teaching skills, dealing with unexpected roles and tasks, and managing time are standard for the instructor, assistant professor, and lecturer groups. Challenges related to research (time, development of skills) and how to advance a career in the academic are common to all ranks.

\section{Institutional Resources}

Resources are grouped according to three clusters: teaching development, workload/research support and infor- mation, and flexibility/rewards and benefits. Table 6 shows the participants' perceived most effective institutional resources. There are also resources viewed to be not effective, not available, or not accessed: mentoring programs $(n=40 ; 44.5 \%)$, paid or unpaid research leave $(n=52 ; 57.80)$, protected time for research $(n=51 ; 56.70 \%)$, assistance in obtaining research grants $(n=46 ; 51 \%)$, and rewards for good research $(n=45 ; 50 \%)$.

All clusters of institutional resources are most effective for the instructor, assistant professor, and lecturer groups. Travel funds to present papers as an institutional resource is most effective for the associate professor and professor groups.

\section{Relationship Supports}

Relationship supports include those from the institution and department. Participants viewed all relationship supports $(n=15)$ to be effective. Table 6 shows examples of relationship supports that were perceived to be the most effective.

\section{Productivity}

Productivity is measured by the number of outputs for teaching, research, and service. Mean number of outputs for teaching is the highest $(M=2.33, S D=1.71)$. Mean number of outputs for research $(M=0.59, S D=0.61)$ and service $(M=0.57, S D=0.57)$ are low. For teaching, the group is most productive in designing examinations and assessments, advising and mentoring students, and developing learning resources. Recognition for teaching in the form of awards is the lowest (Figure 3).

For research, productivity is reflected in advising/ mentoring students with research projects, reviewing research proposals and manuscripts, and attending national conferences. Low productivity for publishing (papers, books, conference papers) is evident (Figure 4). Service productivity is reflected in involvement in service activities or projects

Table 5. Profile of Challenges $(N=90)$

\begin{tabular}{|c|c|c|c|c|c|c|}
\hline Challenge Clusters & Most experienced challenge & $\mathbf{n}$ & $\%$ & Least experienced challenge & $\mathbf{n}$ & $\%$ \\
\hline $\begin{array}{l}\text { Balancing } \\
\text { multiple roles }\end{array}$ & $\begin{array}{l}\text { Need to develop research skills and competencies } \\
\text { Need to develop teaching skills } \\
\text { Designing effective lectures, exams, teaching- } \\
\text { learning activities } \\
\text { No time for research } \\
\text { Managing time } \\
\text { Dealing with unexpected roles and tasks }\end{array}$ & $\begin{array}{l}75 \\
75 \\
68\end{array}$ & $\begin{array}{l}94.40 \\
86.68 \\
84.44 \\
83.33 \\
83.33 \\
75.56\end{array}$ & $\begin{array}{l}\text { Managing teaching load } \\
\text { Conflict in priorities } \\
\text { Stress balancing expectations } \\
\text { Stress with added responsibilities }\end{array}$ & $\begin{array}{l}34 \\
33 \\
29 \\
28\end{array}$ & $\begin{array}{l}38.20 \\
37.08 \\
32.22 \\
31.46\end{array}$ \\
\hline Career advancement & $\begin{array}{l}\text { Stress on how to advance career } \\
\text { Desire to be recognized for accomplishments } \\
\text { Difficulty choosing or developing area of expertise }\end{array}$ & $\begin{array}{l}71 \\
55 \\
51\end{array}$ & $\begin{array}{l}78.90 \\
61.00 \\
56.70\end{array}$ & & & \\
\hline Shift of roles & $\begin{array}{l}\text { Emotional stress due to workload or work conditions } \\
\text { Adjusting from clinician to faculty role } \\
\text { Adjusting from student to faculty role } \\
\text { Doubting competence as faculty }\end{array}$ & $\begin{array}{l}75 \\
72 \\
66 \\
63\end{array}$ & $\begin{array}{l}83.33 \\
80.00 \\
74.16 \\
70.79\end{array}$ & Hesitating to seek assistance & 53 & 58.90 \\
\hline $\begin{array}{l}\text { Embracing academic } \\
\text { culture and } \\
\text { expectations }\end{array}$ & $\begin{array}{l}\text { Pressure to meet expectations or standards } \\
\text { Surprise with academic environment } \\
\text { Pressure to meet promotion requirements }\end{array}$ & $\begin{array}{l}64 \\
60 \\
60\end{array}$ & $\begin{array}{l}71.11 \\
66.67 \\
66.67\end{array}$ & $\begin{array}{l}\text { Strain working with peers } \\
\text { Strain working with senior faculty } \\
\text { Strain working on or developing } \\
\text { relationships with other individuals }\end{array}$ & $\begin{array}{l}57 \\
52 \\
50\end{array}$ & $\begin{array}{l}63.33 \\
57.90 \\
56.18\end{array}$ \\
\hline
\end{tabular}


Table 6. Profile of Institutional Resources and Relationship Supports ( $N=90$ )

\begin{tabular}{llcc} 
Institutional Resource Cluster & \multicolumn{1}{c}{ Most effective institutional resources } & $\mathbf{n}$ \\
\hline Teaching Development & Availability of resources for teaching & 77 & 85.60 \\
& Orientation programs & 72 & 80.00 \\
& Peer observation of teaching & 61 & 67.80 \\
\hline Workload/Research Support & Workload policy & 64 & 71.90 \\
and Information & Information about criteria for promotion and tenure & 60 & 66.70 \\
& Limit on service obligations & 50 & 55.60 \\
& Travel funds to present paper & 48 & 53.33 \\
\hline Flexibility/ Rewards and & Flexible working hours & 72 & 84.71 \\
Benefits & Opportunity to gain advance qualifications & 69 & 76.70 \\
& Attractive salary and benefits & 66 & 74.20 \\
& Opportunity to work from home & 62 & 68.90 \\
\hline Relationship Support Cluster & & Most effective relationship support & $\mathbf{n}$ \\
\hline From the Institution & Good communication between university management and academic staff & 81 & 90.00 \\
& Opportunities to participate in decision-making process & 80 & 89.90 \\
& Opportunities to meet other faculty within institution & 79 & 87.80 \\
\hline From the department & A department head who is committed to success & 80 & 88.90 \\
& Senior colleagues who are interested in faculty's progress & 86.70 \\
& Opportunities to make decisions regarding direction of teaching and research & 77 & 85.60 \\
\hline
\end{tabular}

such as volunteering in professional organizations and other agencies (Figure 5). The majority $(n=36)$ are involved in $1-2$ service projects. Twenty-nine are engaged in 3 or more projects. Some faculty $(n=14)$ have been recognized for their service work within their institutions and by nongovernment and national agencies through awards.

In summary, this group of Filipino OT educators encounters challenges in the fulfillment of roles related to balancing multiple roles, advancing their careers in the academe, shifting of roles, and embracing the academic culture. Available institutional resources and relationship supports are found to be effective. Institutional resources such as mentoring and those related to building research competencies need to be made available or accessed. Productivity is higher for teaching compared to research and service.

\section{Capacity Building Strategies Based on Characte- ristics and Challenges}

The profile of the OT faculty necessitates a systematic, sequential, and long-term approach to capacity building. Even if their paramount competence gap is on research productivity, these next-generation educators must be holistically capacitated with the appropriate personal, social, teaching, administrative, and professional competencies. Based on the characteristics and challenges identified, the following capacity-building strategies are recommended.

\section{Communities of practice to build educator capacity}

Similar to Beane-Katner's ${ }^{4}$ study, Filipino OT educators can be mentored through the faculty learning community (FLC) initiative. Integral to these may include engaging them in decision-making conversations such as

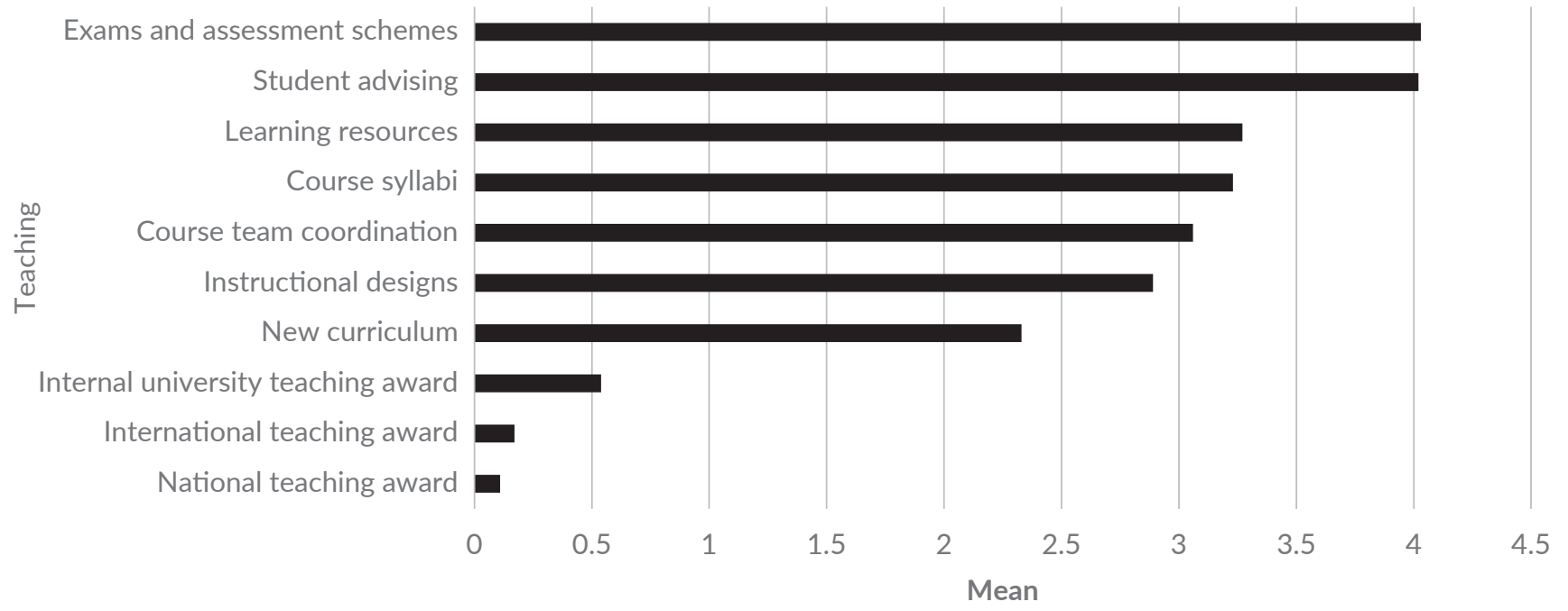

Figure 3. Teaching Productivity. 


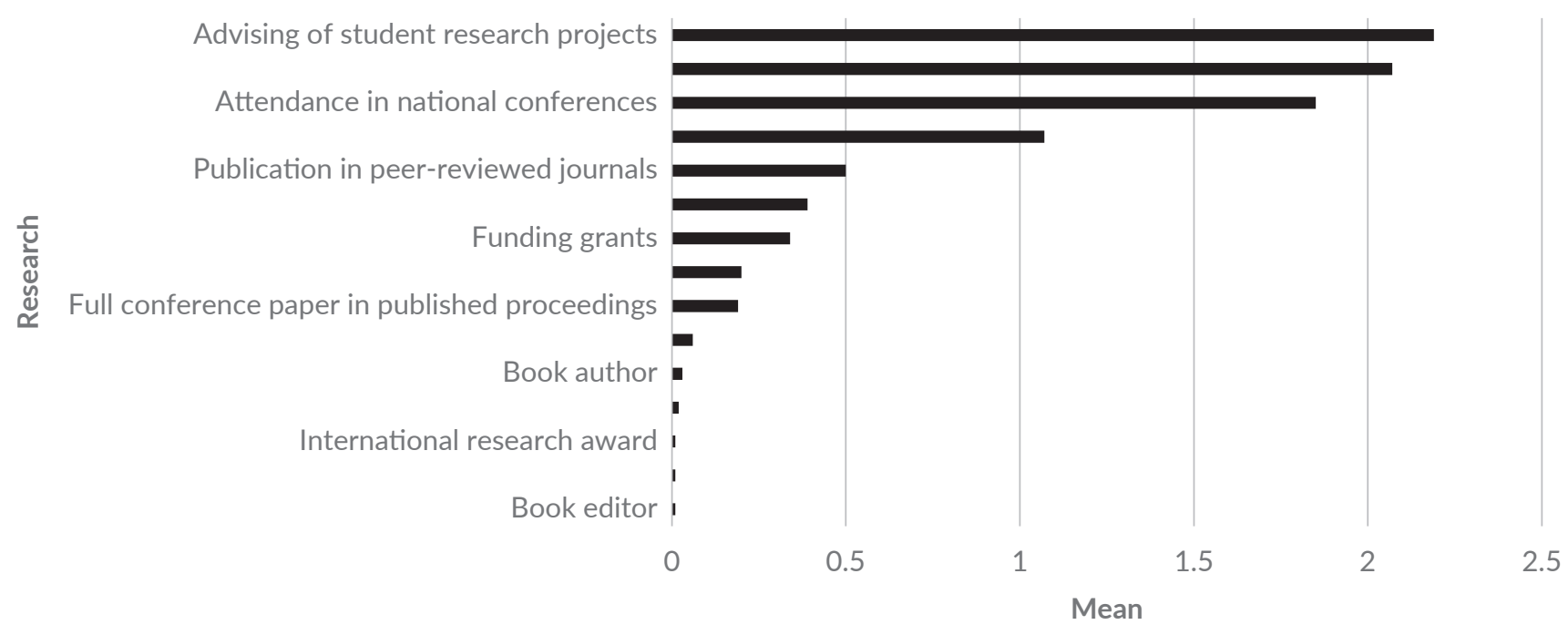

Figure 4. Research Productivity.

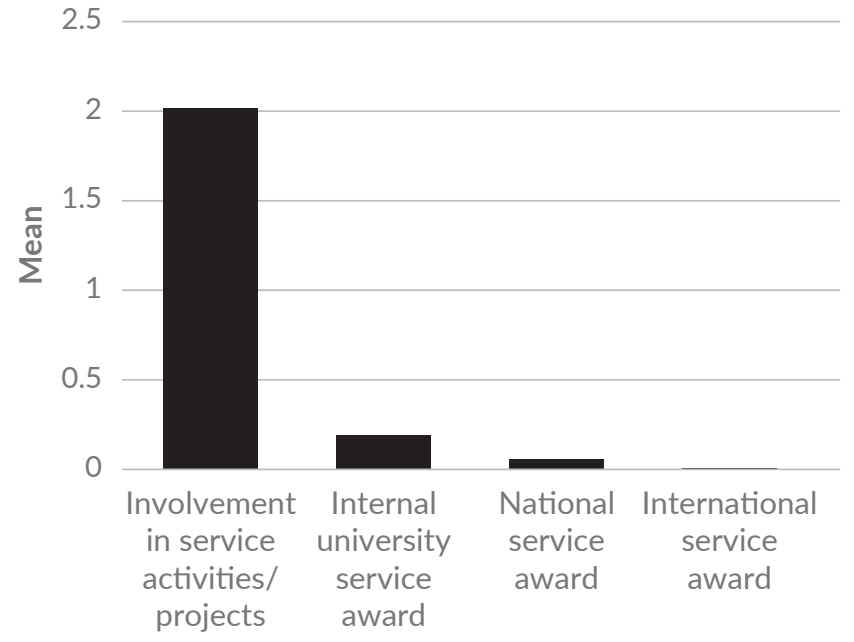

Service Activities

Figure 5. Service Productivity.

curricula development and policymaking in their respective institutions. ${ }^{10}$ Another strategy is to organize activities that will socialize full-time and part-time faculty with the culture of their respective institutions. Formal and informal interactions with peers, senior colleagues, non-academic staff, and students will foster a sense of community and strengthen their identity as academics. A community approach can be developed and customized to the needs and characteristics of early-career academics, and with institutional goals.,13 The interactive nature of the community approach can be provided across projects, functions, and learning environments. ${ }^{4}$ Mentoring using the community approach is characterized by sharing, reflection, community building, coaching, and leadership development and resonates with the needs of next-generation faculty. ${ }^{4}$ Bunkowski and Anderson $^{6}$ described a mentoring network wherein they developed a series of group orientations and professional development sessions, supplemented with mentoring options (peer, e-mentoring) for faculty in the first year of academic appointment. This mentoring network also aimed to support faculty to meet tenure requirements. Strategies to manage/ balance workload, make smart decisions on priorities (e.g., service commitments), and to respond positively to feedback were addressed. ${ }^{6}$

The American Occupational Therapy Association's Academic Education Special Interest Section (AESIS) developed a mentoring program for new educators and academic fieldwork coordinators using a community approach. ${ }^{13}$ Over five to six months, mentees and mentors had video conference meetings and conversations on a variety of topics and issues that mentees identified to be important to their transition to the academe. Feedback from program participants included a better understanding of educational roles, process, and academic community. ${ }^{13} \mathrm{~A}$ community approach is a realistic option for Philippine OT educators in consideration of the paucity of resources. The PAOT, along with educator-members, and school administrators, may develop a similar program.

\section{Supports to build research capacity and engagement}

Evidence from literature shows that the institutional environment is critical in fostering a research culture..$^{19,20}$ Early-career academics will benefit being in an organizational culture that values and engages in research and having access to research and scholarship routes. ${ }^{19}$ This includes having research-oriented departments that communicate clear goals, research agenda and promote the development of a scholar identity. ${ }^{19}$ Access to funding, protected time for research, and participation in research colloquia and scientific conferences strengthen orientation towards research. Incentives such as publication awards and research dissemination grants have been used by universities to increase research productivity. 
Postgraduate and other forms of training open opportunities for early career academics to join and network with research teams and seasoned researchers, including those in other disciplines. ${ }^{6}$ Early career academics may be assigned to key research tasks to build their confidence, and self-efficacy. ${ }^{7}$ Early career academics aspire for recognition for their achievements, even in teaching and service. Recognition in the form of awards and incentives have been reported as empowering and fostered job satisfaction. ${ }^{7}$

\section{Professional Development Programs}

Faculty development programs that address pedagogy, curriculum development and evaluation, research capacity, and leadership are of utmost importance for early career academics. ${ }^{12}$ Capacity building programs may range from formal advanced graduate degree programs to short-term workshops. Experienced educators and researchers from other health professions may be tapped to serve as resource persons to assist in the development of such programs. Advanced degree programs on a distance or blended learning modes are workable options. Access to funding for short-term courses or tuition fee privileges will encourage attendance in professional development endeavors.

\section{Explicit support from academic leaders}

Leaders need to provide targeted supports for new and early career academics. Leaders are encouraged to familiarize themselves with the needs of their faculty specifically in terms of the supports that they need and how and where to access these supports. ${ }^{32}$ This includes being aware of the challenges that they have to deal with and reinforcing institutional resources and relationship building opportunities.

\section{Faculty initiatives}

New and early career academics must also take a proactive stance to build their careers. Personal initiatives to determine their needs to adapt to their roles and take responsibility for their professional development is essential. It will also help to develop an adaptive faculty identity, one that is flexible and adaptive to institutional context and the ability to keep a comfortable level of balance in carrying out roles and responsibilities. Initiating a conversation with the head of the department and/or mentor about five-year goals will facilitate a realistic and practical personal action development plan, one that incorporates the department and institution goals and mission. Another is seeking information on available scholarship programs for advanced studies within and outside their academic institutions (e.g., CHED, international scholarships).

\section{DISCUSSION}

The group of educators who participated in this study represents the next-generation faculty of the Philippine OT academic workforce. This snapshot profile reveals their demographic and academic characteristics, role expectations and demands, challenges, institutional resources, relationship supports, and productivity. The majority are young adults, female, single, part-time, and in the novice to early career stage. In terms of gender and age group, this group is similar to the sample in Foy's ${ }^{16}$ where the majority were also female and transitioned to academia between the ages of $29-34$ years. A notable difference in the profile is that the highest educational degree of the majority of the sample in this present study is at the bachelor's level. In contrast, the majority in Foy's ${ }^{16}$ study entered the academe with a master's degree.

This academic characteristic of this study's faculty participants differ in the standard literature definition of early career academics and practice in other countries, that is, the first five years of academic appointment after completing $\mathrm{PhD}$ or new academics who are undertaking a doctorate. ${ }^{7}$ This difference is due to the higher entry requirements to the academe in other countries (e.g., United States). The fact that a bachelor's level is still recruited in Philippine OT schools reflects the small number of Filipino OT practitioners with advanced degrees. Also, in the Philippines, a bachelor's degree and licensure are adequate qualifications for practice. This academic background may also be due to the clinical practice focus of the bachelor's education. This situation may change in the next ten years due to an explicit advanced degree provision for faculty required in the CHED's Policies, Standards and Guidelines for the BSOT program. ${ }^{26}$ This is evident in the significant number of faculty completing and planning to pursue advanced degrees within the next three years. This can be viewed as a positive development for OT education and upholds the position that upgrading of faculty qualifications of Filipino OT educators must be sustained.

Similar to this study, there has been an increase in the hiring of part-time and non-tenure track faculty in other countries and disciplines. ${ }^{1}$ Because many work on a semesterby-semester basis for a few days or hours per week, they face many issues such as the lack of job security, paid leave entitlements, salaries that are based on an hourly formula, and limited access to professional development resources. ${ }^{15}$ Additional supports may be needed for contract or parttime faculty, to address their needs, such as developing their pedagogical skills. ${ }^{15}$

Although expected to fulfill many roles, the literature supports findings that next-generation academics' foremost responsibility is teaching. ${ }^{11}$ This explains the challenges related to the teaching role: adjustment from clinician to faculty roles, doubting their educator competence, designing effective lectures, exams, and other teaching-learning activities..$^{8-9,18}$ It appears that the academic identity of Filipino OT educators is anchored on teaching, which may primarily be due to their work environments where teaching is given premium value. Teacher identity needs to be nurtured and strengthened, even in a higher education context 
where research and scholarship are accorded more value. ${ }^{12}$ Competence as educators was identified to be a unique predictor of engagement among early-career academics in an Australian university ${ }^{5}$, and this supports other academic scholars' argument that building capacity in pedagogy for this faculty group is essential. ${ }^{10}$ For Philippine OT education, an influential teacher identity is especially crucial if educators are to carry out their mission of producing a critical mass of OT graduates, as envisioned by the WHO and PAOT in the next five to ten years. Moreover, educators need to recognize their role in advancing OT as an academic discipline through research and scholarship.

Next-generation faculty are also challenged with balancing teaching, research, and service demands. ${ }^{8-10}$ Except for a few, research engagement has been confined to supervising student theses for this group of Filipino OT educators. This group reported harnessing competencies in research as a challenge, and there is an apparent lack of resources related to research. This suggests that supervising student theses is a responsibility they fulfill, despite the lack of research skills. The recognition of a lack of confidence in research skills has also been reported in literature. ${ }^{22}$ This challenge may be related to the pressure to meet expectations and demands imposed by the academic environment and aspiration to advance academic careers ${ }^{20}$ lack of postgraduate education, and availability and access to resources related to research. ${ }^{19}$

Study participants found information about promotion and tenure to be a useful institutional resource. This finding is critical as other studies have reported that the lack of information on promotion and tenure has resulted in frustration and perceptions of incompetence. ${ }^{16}$ Formal and informal mentoring is reported as not available or not accessed. Academic institutions will need to re-design orientation, mentoring, and professional development programs to make it appealing to new faculty's interests, characteristics, and strengths. ${ }^{6}$

Relationship supports, although available and found compelling by the group, is a critical aspect to making a professional decision to commit to the academe. ${ }^{10}$ This is particularly pertinent to Filipino OT educators, with the reasons cited for joining the academe. One strategy for new academics to commit to the academe is by involving them in decision-making, such as curricula development and policymaking in their respective institutions. ${ }^{10} \mathrm{OT}$ faculty in Wright et al.'s ${ }^{18}$ study reported that contributing to the curriculum and being stimulated intellectually facilitated their fitting into the academe.

Their teaching productivity is reported as higher compared to research and service. Many of the study participants spend more than $50 \%$ of their time on teaching. This suggests that teaching is the primary role and expectation of Philippine OT schools and that many of these institutions may not require research for promotion and tenure. A small number of this sample, those with advanced postgraduate degrees, and who have gained tenure, are building their research and scholarship portfolios, consistent with early career aspirations. This supports the argument that postgraduate training is a factor in building research efficacy among early career academics. ${ }^{7}$ In addition to the lack of postgraduate education, teaching load has been reported to have a negative influence on research productivity. Hence, this may account for the group's low productivity in research. ${ }^{11}$ Compared to OT faculty in Canada, Hong Kong, and the United States ${ }^{21}$, research productivity of this group is critically low. This is an important finding, considering that research and scholarship are essential in the advancement of the discipline in the country. The need for next-generation academics to upgrade research skills and competencies is thus a crucial undertaking. ${ }^{20}$

Filipino OT educators are unique in the sense that despite their academic profile, they appear to have the motivation to help sustain OT education in the country, are aware of their limitations, and need a tremendous amount of support. The strategic capacity building initiatives we propose are underpinned by the characteristics and needs of the next-generation Filipino OT educators. The findings of this study show that it is imperative for OT programs and the national organization to consolidate efforts to assist the nextgeneration faculty build capacity that focus on mitigating the challenges, improving productivity, and highlighting the value of institutional resources and relationship supports, upgrading faculty qualifications, and fostering a commitment to an academic career.

\section{Study Limitations}

This study has several limitations. Our sample included only about half of Filipino OT educators. We exhausted efforts to increase participation to ensure that the sample represented schools from all the different regions of the country. Caution must be taken in terms of generalizing results of the study, considering that this group represents the accessible OT educator population. We focused only on aspects of their academic practice (e.g., academic profile, challenges) and collected data at a single point in time. The proposed capacity-building strategies are not exhaustive. We did not explore salaries, turn-over trends, recruitment and retention, and faculty development programs.

\section{Future Research Directions}

The profile of academic educators will have to be updated periodically as academic careers evolve. Future studies may highlight other aspects of academic life, such as compensation and turn-over trends, recruitment and retention strategies, and faculty development programs. Longitudinal studies may provide information on how OT faculty careers evolve. Experiences of OT educators in different career stages may provide information on how they are meeting expectations and institutional performance metrics. 


\section{CONCLUSION}

This study is a snapshot of the OT academic workforce in the Philippines. This group of Filipino OT faculty is young, female, and single. The academic profile shows that the majority have bachelor's as their highest educational degree, work part-time, hold the instructor rank, nontenured, and have been in academia for $5+$ years. Although expected to assume several roles, teaching is the preferred and expected role, and more than $50 \%$ of the time is spent on teaching tasks. This group of educators is most productive in teaching. Balancing multiple roles and how to advance their academic career are their most prominent challenges. Although institutional resources and relationship supports are available, those related to research are wanting.

The next-generation Philippine OT academic workforce is mostly in the novice or early career stage, a group that needs professional development to build capacity and advance their academic careers. The results of this study can serve as a prompt for continuing discourse on how to develop, retain, and strengthen the next generation of OT educators in the country and other parts of the globe. This present study contributes to the body of literature on the OT academic workforce from an emerging economy.

\section{Acknowledgment}

Our heartfelt thanks to the Filipino OT academic educators who participated in this study.

A Local Doctoral Fellowship Program supported the first author under the Faculty, REPS, and Administrative Staff Development Program of the University of the Philippines System.

\section{Statement of Authorship}

All authors participated in the conceptualization of the study, data analysis, and writing of the manuscript. All authors approved the final manuscript version.

\section{Author Disclosure}

All authors declare no conflicts of interest.

\section{Funding Source}

The first author was supported by a Local Doctoral Fellowship under the Faculty, REPS and Administrative Staff Development of the University of the Philippines System.

\section{REFERENCES}

1. Kezar A, Maxey D, Holcombe E. The professoriate reconsidered [Internet]. California: University of Southern California-Pullias Center for Higher Education, Rossier School of Education; 2015 [cited 2020 March]. Available from: https://pullias.usc.edu/wpcontent/uploads/2015/10/Professoriate-Reconsidered-final.pdf

2. Cabatan MC, Grajo LC, Sana EA. A scoping review of challenges and the adaptation process in academia: Implications for occupational therapy educators. Open J Occup Ther. 2019; 7(1): Article 8. http:// doi.org/10.15453/2168-6408.1523
3. Beane-Katner L. Developing the next generation of faculty: Taking a learning community approach. J Cent Teach Learn. 2013; 5: 91-106.

4. Beane-Katner L. Anchoring a Mentoring network in a new faculty development program. Mentor Tutoring. 2014;22(2):91-103. http:// dx.doi.org/10.1080/13611267.2014.902558

5. Bunkowski L, Anderson S. A mentoring network for 21st century faculty. J Educ Soc Policy. 2017; 4 (3): 1 - 12.

6. Crome E, Meyer L, Bosanquet A, Hughes L. Improving engagement in an early career academic setting: Can existing models guide early career academic support strategies? High Educ Res Dev. 2019; https://doi.org/10.1080/07294360.2019.1576597

7. Hemmings B, Hill D, Sharp JG. Critical interactions shaping early career development in two higher education institutions. Issues Educ Res. 2013; 23(1): 35-51.

8. Hurst KM. Experiences of new physiotherapy lecturers making the shift from clinical practice into academia. Physiotherapy. 2010; 96: 240 -7. http://dx.doi.org/10.1016/j.physio.2009.11.009

9. Murray C, Stanley M, Wright S. The transition from clinician to academic in nursing and allied health: A qualitative meta-synthesis. Nurs Educ Today. 2014; 34: 389-295. http://dx.doi.org/10.1016/ j.nedt2013.06.010

10. Hollywood A, McCarthy D, Spencely C, Winstone N. 'Overwhelmed at first': the experience of career development in early career academics. J Furth High Educ. 2019; https://doi.org/10.1080/ 0309877X.2019.1636213

11. Hemmings BC. Strengthening the teaching self-efficacy of early career academics. Issues Educ Res. 2015; 25(1): 1-17. http://www.iier.org. au/iier25/hemmings.html

12. McCune V. Academic identities in contemporary higher education: sustaining identities that value teaching. Teach High Educ. 2019; https://doi.org/10.1080/13562517.2019.1632826

13. Silva P, Noguiero T, Saraiva M, Jorge F, Radzeviciene A, Chuong T. A capacity building for higher education Erasmus+ Project: Strategic human resources management for Southeast Asian Universities (HR4ASIA). 2018 July; https://doi.org/10.21125/edulearn.2018.1699

14. Simon R, Krug G, Grajo L. Developing a mentorship program for new educators and academic fieldwork coordinators using a community approach. SIS Quarterly Practice Connections. 2019 May; 4(2): 11-13.

15. Lockhart-Keene L, Potvin MC. Occupational therapy adjunct faculty self-perceptions of readiness to teach. Open J Occup Ther. 2018; 6(2): Article 14. https://doi.org/ 10.15453/2168-6408.1415

16. Foy C. Identifying barriers and pathways to success for new occupational therapy faculty members: A pilot survey. Occup Ther Health Care. 2017; http://doi.org/10.1080/07380577.2017.1354269

17. Harvison N, Taff S, Grajo L, Hooper B. Imagining the occupational therapy educational landscape in 2050. In: Taff S, Grajo LC, Hooper, BR, eds. Perspectives on occupational therapy education: Past, present, and future. Thorofare, NJ: SLACK; 2020. pp. 223-9.

18. Wright S, Stanley M, Murray C. Weighing up the commitment: A grounded theory of the transition from occupational therapy clinician to academic. Aust Occup Ther J. 2014; 61: 437-445. https://dx.doi. org/10.1111/1440-1630.12146

19. Boyd P, Smith C. The contemporary academic: Orientation towards research work and researcher identity of higher education lecturers in the health professions. Stud High Educ. 2016; 41(4): 678-95.

20. Fortune T, Ennals P, Bhopti A, Nielson C, Darzins S, Bruce C. Bridging identity 'chasms': occupational therapy academics' reflections on the journey towards scholarship. Teach High Educ. 2016; http://doi.org/10.1080/13562517.2016.1141289

21. Man D, Tsang W, Lu EY, Tsang H. Bibliometric study of research productivity in occupational therapy and physical therapy/ physiotherapy in four Western countries and five Asian countries/ regions. Aust Occup Ther J. 2019; http://dx.doi.org/ 10.1111/14401630.12608

22. Stoykov ME, Skarupski KA, Foucher K, Chubinskaya S. Junior investigators thinking about quitting research: A survey. Am J Occup Ther. 2017; 71(2): 7102280010p1-7102280010p7. http://dx.doi. org/10.5014/ajot.2017.019448 
23. Cabatan MC, Duque RL. Perspectives on occupational therapy education in Southeast Asia. In: Taff S, Grajo LC, Hooper BR, eds. Perspectives on occupational therapy education: Past, present, and future. Thorofare, NJ: SLACK; 2020. pp.143- 51.

24. World Health Organization, Rehabilitation 2030: A Call for Action [Internet]. 2017 [cited $2020 \mathrm{March}$ ]. Available from: http://www. who.int/disabilities/care/Rehab2030MeetingReport_plain_text_ version.pdf

25. World Federation of Occupational Therapists, Minimum standards for the education of occupational therapists [Internet]. 2016 [cited 2020 March]. Available from:https://www.wfot.org/assets/ resources/COPYRIGHTED-World-Federation-of-OccupationalTherapists-Minimum-Standards-for-the-Education-ofOccupational-Therapists-2016a.pdf

26. Commission on Higher Education, Policies, standards, and guidelines for the Bachelor of Science in Occupational Therapy Education (BSOT) program (CMO No. 52, Series of 2017) [Internet]. 2017 [cited 2020 March]. Available from: https://ched.gov.ph/wp-content/ uploads/2018/04/CMO-No.-52-Series-of-2017-Policies-Standardsand-Guidelines-for-the-Bachelor-of-Science-in-OccupationalTherapy-Education-BSOT-Program.pdf

27. Grecia A. President's Message. Paper presented at the 52nd annual convention of the Philippine Academy of Occupational Therapists, Inc., Century Park Hotel, Manila, Philippines. 2017.

28. Republic Act 11223. Universal Health Care Act. An act instituting Universal Health Care for all Filipinos prescribing reforms in the health care system, and appropriating funds therefor. [Internet]. 2019 [cited 2020 March]. Available from: https://www.officialgazette. gov.ph/downloads/2019/02feb/20190220-RA-11223-RRD.pdf
29. Lorenzo F, Dela Rosa J, Ronquillo K, Mercado R, Villegas S. Philippines Mobility of Health Professionals. Manila: Institute of Health Policy and Development Studies, National Institutes of Health, University of the Philippines Manila; 2012.

30. Grajo L, Boiselle AK, Dalomba E. Defining the construct of occupational adaptation. In: Grajo L, Boiselle AK, eds. Adaptation through Occupation-Multidimensional Perspectives. Thorofare, NJ: Slack Incorporated; 2019. pp. 3 - 18 .

31. Fowler F. Survey research methods, 5th ed. Thousand Oaks, CA: SAGE; 2014.

32. Kaufman RR. Career factors help predict productivity in scholarship among faculty members in physical therapist education programs. Phys Ther. 2009; 89 (3): 204-16.

33. Sutherland K, Wilson M, Williams P. Research report: Success in academia? The experiences of early career academics in New Zealand universities. Wellington, NZ: Ako Aotearoa National Centre for Tertiary Teaching Excellence; 2013.

34. Cabatan MC, Grajo LC, Sana EA. Development and content validation of the Adaptation Process in Academia Questionnaire for Occupational Therapy Educators. Acta Med Philipp. 2020; 54(2): $142-50$. 